\title{
POSSIBILIDADES METODOLÓGICAS PARA UM ENSINO (CRÍTICO!) DE HISTÓRIA NO ENSINO FUNDAMENTAL
}

\author{
METHODOLOGICAL POSSIBILITIES FOR A (CRITICAL!) \\ TEACHING OF HISTORY IN ELEMENTARY SCHOOL
}

Tassio Acosta 1

\author{
Recebido: 15 abr. 2019 \\ Aceite: 17 jun. 2019 \\ DOI https://doi.org/10.29327/2.1373.1-5
}

\begin{abstract}
Resumo: Frente à necessidade de se pensar em abordagens metodológicas diversificadas para um ensino de História mais interessante, cooperativo e colaborativo entre discentes, este artigo busca pensar na utilização das Histórias Local, Oral, Histórias em Quadrinhos (HQs) e na abordagem das questões afro-brasileiras para o Ensino Fundamental com o objetivo de obter uma abordagem crítica, embasada e referenciada pelos Parâmetros Curriculares Nacionais (PCNs). Recomenda-se uma série de abordagens metodológicas existentes nos PCNs, mas também as exemplifica e demostra formas de inseri-las no cotidiano escolar. Seu objetivo principal é trazer novas possibilidades e pensamentos para uma prática docente interessante e crítica, enriquecendo o empoderamento dos sujeitos por meio de suas próprias realidades e contextos.
\end{abstract}

PALAVRAS-CHAVE: Ensino de história; PCN, História oral; História local; História em quadrinhos.

\begin{abstract}
In the face of the need to think of diversified methodological approaches to a more interesting, cooperative and collaborative History teaching among students, this article seeks to think about the use of Local, Oral, Comic Stories (HQs) focusing on afro-brazilian issues aimed at Brazilian students for Elementary School with the objective of obtaining a critical approach, based and referenced by the National Curricular Parameters (PCNs). A number of methodological approaches are recommended in the NCPs, but it also exemplifies and demonstrates ways of incorporating them into everyday school life. Its main objective is to bring new possibilities and thoughts to an interesting and critical teaching practice, enriching the empowerment of the subjects through their own realities and contexts.
\end{abstract}

KEYWORDS: History teaching; PCN, Oral history; Local history; Comics.

\footnotetext{
1 Doutorando em Educação pela Universidade Estadual de Campinas (UNICAMP). Docente no Instituto Federal de São Paulo (IFSP). E-mail: tassio.acosta@ifsp.edu.br ORCID iD https://orcid.org/0000-0003-1104-6525
} 


\section{INTRODUÇÃO}

Muitas vezes quem se com docentes de Ensino Fundamental I infantilizando seus alunos e tratando-os de forma que seus conhecimentos e visões de mundo são desqualificados em virtude da pouca idade. No entanto, pode-se deparar também com o extremo oposto disso: docentes 'adultilizando' seus alunos ao não permitirem que as suas visões de mundo sejam diferentes das dele, exigindo uma maturidade intelectual não condizente com suas idades. A utilização dos mais diversos materiais e métodos, além dos obrigatórios como, por exemplo, os livros didáticos e/ou sistemas apostilados, cria a possibilidade de que um ensino crítico de História possa ser desenvolvido em sala de aula de forma a aumentar o interesse dos alunos pela matéria.

Reconhece-se que a escolha dos conteúdos dos livros oficiais se dá de forma tal que não existe um ensino apolítico, visto que quando um tema é posto em um livro didático em detrimento de outro, esta escolha já implica um posicionamento político. Os conteúdos excluídos costumam ser aqueles que causam desagrado à classe dominante, que não quer ver reveladas as suas histórias sem o véu romantizado que as encobre. O reconhecimento de que o pessoal é político (HANISC, 1969) é uma forma de colocar em debate o papel do sujeito na construção da História.

A escolha dos temas a serem trabalhados em sala de aula deve considerar primariamente o interesse que aquela comunidade pode desenvolver por ele. Para que isso seja possível, deve-se levar em consideração uma série de fatores como, por exemplo, a necessidade de reuniões pedagógicas, a análise da localidade onde a escola está inserida, suas especificidades regionais etc. Fernandes (1995) afirma que a história local possibilita um "resgate às peculiaridades e especificidades regionais e dê conta da pluralidade étnico-cultural de nossa formação histórica (p. 46).

A troca de relatos e experiências entre os docentes que já atuam naquela escola pode propiciar uma leitura mais crítica sobre o corpo discente e docente, considerando que o "tempo de casa" de um docente não significa necessariamente que ele desenvolva um bom trabalho. $\mathrm{O}$ 
profissional deve se atentar à qualidade crítica do corpo docente escolar e buscar desenvolver trabalhos que aumentem o interesse discente pelo ensino das Histórias.

Portanto, este artigo busca analisar e fornecer subsídios para que diferenciais no ensino de História possam ser desenvolvidos de forma crítica nas escolas de Ensino Fundamental I e assim possibilitar maior interesse discente.

\section{PARÂMETROS CURRICULARES NACIONAIS (PCNS)}

Em seu primeiro parágrafo sobre os conteúdos e ciclos de ensino, vê-se que em relação ao ensino e à aprendizagem de História previstos para as séries do primeiro ciclo, recomenda-se:

O ensino e a aprendizagem da História estão voltados, inicialmente, para atividades em que os alunos possam compreender as semelhanças e as diferenças, as permanências e as transformações no modo de vida social, cultural e econômico de sua localidade, no presente e no passado, mediante a leitura de diferentes obras humanas. (BRASIL, 1997, p. 39)

Desta forma, entende-se que o objetivo é que, considerando a visão e as perspectivas de mundo da criança, ela possa começar a criar subsídios e a olhar de forma diferenciada para que se torne capaz de criar correlações entre aquilo que compreende enquanto mundo e aquilo com o que ela terá contato por meio dos materiais e métodos diversos existentes em sala de aula. Entretanto, a ausência de criticidade possibilita que o passado apareça "de maneira a homogeneizar e a unificar as ações humanas na constituição de uma cultura nacional” (NADAI, 2009, p. 32).

Dentre as diversas possibilidades de ensino, compreende-se que haja a necessidade do estímulo à criticidade perante as suas visões de mundo, com o objetivo de torná-las capazes de olhar mais atentamente para o mundo ao seu redor, (re)conhecendo os marcadores das diferenças e fomentando possibilidades de melhorias para que as vidas se tornem mais vivíveis.

Ao debater quais vidas merecem ser vividas, Judith Butler (2015) traz, à luz do debate, por que choramos por algumas vidas e não nos importamos com outras. Fato esse correlacionado à 
ausência de criticidade que temos não apenas com a vida, mas também com a insuficiente, ou até mesmo inexistente criticidade ensaiadas nos ensinos escolares.

O direcionamento dado pelo docente em relação aos conteúdos didáticos influenciará consideravelmente as percepções de mundo da criança, a qual será sujeita a constantes construções e ressignificações. Coll (2004, p.129) afirma que "essa responsabilidade da escola e dos professores não pode fazer com que se esqueça de que a motivação é moldada em contextos não escolares, como a família, a classe social e a cultura.". Sendo assim, aponto para a necessidade de frisar que o docente não tem total influência perante a visão de mundo que será desenvolvida pela criança, visto que a escola é apenas um dos diversos pilares de formação da subjetividade discente.

Ao mostrar que nós somos sujeitos de nossas histórias e fazemos parte de uma ampla relação de poder, mostrar-se-á, também, que todos nós estamos inseridos em outras histórias e esta coexistência faz com que a sociedade interaja entre si - seja positiva ou negativamente, em harmonia ou em desarmonia. Estes tensionamentos sociais sempre existirão, pois envolvem sujeitos com as suas demandas e interesses inerentes.

Para Young (2007), nem sempre as escolas obtêm o sucesso esperado perante a formação discente, visto que há muitas possibilidades de uns alunos terem as suas autonomias e potências mais bem trabalhadas do que outros. A esse fato, ele argumenta que

O sucesso dos alunos depende altamente da cultura que eles trazem para a escola. Culturas de elite que são menos restritas pelas exigências materiais da vida são, não surpreendentemente, muito mais congruentes com a aquisição de conhecimento, independente de contexto, que culturas desfavorecidas e subordinadas. Isso significa que, se as escolas devem cumprir um papel importante em promover a igualdade social, elas precisam considerar seriamente a base de conhecimento do currículo, mesmo quando isso parecer ir contra as demandas dos alunos (e às vezes de seus pais). (p. 1297)

Após compreender os tensionamentos existentes entre sujeitos, sociedade e governos (enquanto instituições), caberá ao docente se atentar para não incorrer na prática etnocêntrica - ou seja, a desvalorização ou subjugação da cultura do outro em relação à sua ou, até mesmo, valorizar a cultura de um grupo social (ou classe social) em detrimento de outro. 
Um dos maiores objetivos dos PCNs de ensino de História está no intuito de fazer com que os alunos observem o mundo de forma crítica e reconheçam as diferenças existentes não apenas entre si, em sala de aula, mas também em suas localidades. Partindo da necessidade de se fomentar um ensino de História crítico para as séries finais do Ensino Fundamental I, recomenda-se ter como ponto central de análise as próprias realidades para que discentes possam compreender as diferenças existentes entre si e/ou usando outras escolas e localidades como pontos de análise.

Não obstante, dentre os sete objetivos de História para o primeiro ciclo, recomenda-se:

[...] reconhecer algumas semelhanças e diferenças sociais, econômicas e culturais, de dimensão cotidiana, existentes no seu grupo de convívio escolar e na sua localidade; reconhecer algumas permanências e transformações sociais, econômicas e culturais nas vivências cotidianas das famílias, da escola e da coletividade, no tempo, no mesmo espaço de convivência. (BRASIL, 1997, p. 40)

Compreendendo que a escola, a família e a comunidade fazem parte do cotidiano discente, é maior a possibilidade de que as crianças analisem seus contextos e reconheçam as diferenças existentes como, por exemplo, núcleo familiares com pai e mãe, apenas com mãe, avós, homoparentalidade, diferenças étnico-raciais.

Inserir a discussão de gêneros e sexualidades é de extrema urgência para que possamos pensar em novas formas de vivências (Acosta, 2016; Louro, 1998; Junqueira, 2013), para que a ocorrência de atos de intolerâncias e discriminações sejam menos prováveis. Partindo das questões de gênero, o professor poderá discutir a existência de jornada dupla da mãe (que trabalha fora e faz os serviços domésticos), enquanto o homem faz apenas jornada externa à casa, sem ajudar nos afazeres domésticos; a 'obrigatoriedade' de a mulher cozinhar enquanto o homem não é cobrado para ter a mesma responsabilidade; as diferenças na criação de irmãos de gêneros opostos; brincadeiras e brinquedos generificado.

Em relação às questões de sexualidade, inserir o debate referente a núcleos familiares nãoheterossexuais é de grande valia para que as crianças possam compreender não apenas que as sexualidades não-heterossexuais são tão normais quanto a heterossexual, mas também que existem diversas formas de estruturas e organizações familiares para além da heteronormativa. 


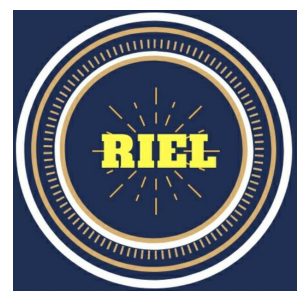

Partindo destes reconhecimentos e diferenciações, o professor terá maiores possibilidades para trabalhar as histórias por meio de diversas abordagens metodológicas, tais como a História local, oral, iconográfica, étnico-racial, das diferenças, para que se desenvolva maior criticidade discente.

\section{METODOLOGIAS DIVERSAS}

\subsection{História local}

Ao assumir que o pessoal é político, recomenda-se se atentar à cultura local para compreender o que costuma ser valorizado em seu cotidiano e como esta valorização pode agregar valores ao ensino de História. Compreender o dinamismo do local onde a escola está situada e de como aquela comunidade se estrutura é uma forma de compreender aquilo que ela costuma valorizar, visto que

[...] uma vez que a configuração da realidade social sofreu profundas transformações e os instrumentos de que se dispunha para explicar a realidade já não respondem a contento, é imperativo que novas abordagens teóricometodológicas sejam desenvolvidas. (ROSSO; BANDEIRA; COSTA, 2002, p. 239)

Dentre as diversas possibilidades teórico-metodológicas, pode-se evidenciar o reconhecimento das especificidades que compõem a cultura local como, por exemplo, a existência de muros pixados 2 e grafitados, rodas de samba, idosos se encontrando nas praças para atividades de lazer, jovens utilizando meios de transportes alternativos como bicicletas e skates. Todas estas especificidades formam o dinamismo daquela comunidade e devem ser reconhecidas e valorizadas pelo docente.

A valorização da produção cultural local (LÓSSIO; PEREIRA, 2007) possibilita a construção de metodologias específicas capazes de ligar os saberes daquela comunidade, a qual o

2 Utiliza-se neste artigo a palavra pixo com "X", ao invés de "CH", por ser uma reivindicação dos artistas que pixam as cidades. 
aluno está inserido, com os saberes escolares contidos nos livros didáticos. Para Malanchen (2013), o desenvolvimento cultural está ancorado na produção de bens e é um resultado da sua existência enquanto sujeitos, desenvolvimento este que está em constante ressignificação.

Independentemente da idade, todos os alunos têm a sua bagagem cultural. O professor deve valorizá-la para que seja possível trazer este conhecimento adquirido em suas formações enquanto sujeitos para dentro da sala de aula, com o intuito de criar a oportunidade de lançar outros olhares em relação à prática do ensino de História. Em uma sala de aula com 30 alunos, o professor terá 30 perspectivas diferentes de análise e esses olhares podem contribuir para que outras interpretações sejam dadas ao conteúdo escolar e para a viabilização de diversos debates. Não é porque os alunos estejam no Ensino Fundamental I que devem ser infantilizados ou ter seus conhecimentos desqualificados. Muito pelo contrário: deve-se valorizar a sua bagagem cultural.

A valorização do capital cultural discente possibilita uma troca de experiências e entendimentos que enriquecem a prática do ensino de História, pois os múltiplos olhares criam novas formas de interpretar o conteúdo que está sendo passado, visto que o conhecimento é estruturado por uma complexa rede construída por meio dos debates e das discussões. O caderno de Pluralidade Cultural, dos Parâmetros Curriculares Nacionais, afirma sobre a importância da valorização cultural:

Partilhar um cotidiano em que o simples "olhar-se" permite a constatação de que todos - alunos, professores e demais auxiliares do trabalho escolar — são provenientes de diferentes famílias, diferentes origens e possuem, cada qual, diferentes histórias, permite desenvolver uma experiência de interação "entre diferentes", na qual cada um aprende e cada um ensina. Traz a consciência de que cada pessoa é única e, por essa singularidade, insubstituível. (BRASIL, 1997, p. 138)

Ressalta-se, entretanto, que o professor poderá se deparar com uma bagagem cultural, tanto de discentes quanto de docentes e gestores escolares, ancorada em preconceitos e discriminações. Neste caso, ele deverá criar metodologias que possibilitem a problematização destes comportamentos com o objetivo de fomentar o respeito às diferenças. 
$\mathrm{Na}$ escola, muitas vezes, há manifestações de racismo, discriminação social e étnica, por parte de professores, de alunos, da equipe escolar, ainda que de maneira involuntária ou inconsciente. Essas atitudes representam violação dos direitos dos alunos, professores e funcionários discriminados, trazendo consigo obstáculos ao processo educacional pelo sofrimento e constrangimento a que essas pessoas se veem expostas. (BRASIL, 1997, p. 122)

A escola deve estar preparada para combater manifestações discriminatórias, visto que a pessoa que sofre este tipo de violência poderá ser prejudicada em seu desenvolvimento educacional e, caso não se combata, tais ocorrências poderão aumentar, ainda mais, as precariedades e vulnerabilidades no ambiente escolar dos alunos vitimados. Por "manifestações discriminatórias", entende-se qualquer prática que atente contra o respeito às diferenças ou ataque os Direitos Humanos.

$\mathrm{O}$ fato de um aluno possuir uma bagagem cultural ancorada em preconceitos e discriminações não significa que o professor não possa intervir. De acordo com os PCNs, o professor não apenas pode, como deve criar intervenções com o objetivo de mitigar a existência de práticas discriminatórias. Portanto, é necessário observar criteriosamente para identificar estes signos e pensar em metodologias para combatê-los. Cita-se, por exemplo, a existência dos etnocentrismos, dos racismos, dos machismos e das LGBTfobias no cotidiano escolar.

Para Carvalho (1997), o etnocentrismo é a criação de um modelo de cultura considerado "correto" e que deve se perpetuar sobre as demais culturais, normalmente subalternizadas e desvalorizadas nas relações de poder. Este tipo de violência é comumente utilizado nos colonialismos cognitivos por meio da violência simbólica, como frisado por Pierre Bourdieu.

Diversas são as existências do etnocentrismo no cotidiano escolar: silenciamento das diferenças e busca pela normatização, desvalorização da cultura popular como as expressões musicais marginalizadas em detrimento da aceitação daquelas midiáticas, desqualificação de artes urbanas, como pixo e grafite, feitas nos muros das cidades, não sendo estas consideradas "artes” e/ ou "manifestações artísticas", gírias de comunidades locais, etc.

Reconhecer as diferenças existentes em sala de aula, bem como a sua pluralidade cultural, são ações que possibilitam o enriquecimento da prática pedagógica, onde estes múltiplos olhares criam novos entendimentos. Para Alves (2006) 
a localidade, seja na sua componente testemunhal seja na arquitectónica, pode constituir um exemplo privilegiado do nosso passado, que aproxima o professor ao aluno, que o enraíza no seu espaço, que o forma criticamente no exercício da sua cidadania e que o aproxima do saber histórico. (p. 69)

Fazer uso desta bagagem cultural existente em sala de aula é uma forma de valorizar os saberes discentes e as suas culturas. Sega (2000) reconhece que "a representação é sempre a atribuição da posição que as pessoas ocupam na sociedade, toda representação social é representação de alguma coisa ou de alguém”. (p. 129). Valorizar esta bagagem ajudará os alunos a criarem sentimentos de pertencimento e a se sentirem representados, tanto em relação a seus pares quanto no reconhecimento às diferenças existentes.

\subsection{História oral}

Jodelet (1990) afirma que a representação social é ancorada em cinco pilares: i) representação de um objeto em específico; ii) caráter imagético; iii) simbolização e representação de algo; iv) valor construtivo e v) autonomia e criatividade. Esses pilares determinam a estruturação e compreensão de uma determinada sociedade como tal. Sendo assim, o professor deve olhar para a sala de aula observando a dinâmica social daquela localidade, preferencialmente, adotando uma perspectiva sociocultural, compreendendo que os sujeitos se constituem a partir daqueles valores.

A utilização da História Oral enquanto ferramenta metodológica permite que histórias locais, como por exemplo aquelas contadas pelas pessoas de mais idade, possam criar significados para os jovens, que até então não as reconheciam como pilares sustentadores de suas próprias culturas, visto que são passados (e interiorizados) entre as gerações por meio das narrativas e muitas vezes desqualificadas pelo saber escolar. Jacques Le Goff (1990) afirma que a memória é de fundamental importância para a análise do passado e do presente, visto que se pode fundamentar as informações contidas nos livros por meio do conhecimento já adquirido em seus cotidianos.

Pode-se fazer uso da História Oral por meio de oficinas, nas quais os alunos convidariam seus familiares com mais idade para contar as suas histórias, como era o bairro décadas atrás, a 


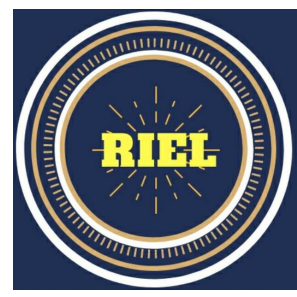

relação que a comunidade criou com o bairro e como se relacionam entre si, assim como também criar possibilidades de analisar se há algum vínculo entre a comunidade local e a escola, ou até mesmo se houve algum processo de exclusão ou aproximação durante a sua construção.

Os lugares da memória, então, podem ser considerados esteios da identidade social, monumentos que têm, por assim dizer, a função de evitar que o presente se transforme em um processo contínuo, desprendido do passado e descomprometido com o futuro. [...] Além de contribuir para a construção/reconstrução da identidade histórica, a história oral empreende um esforço voltado para possibilitar o afloramento da pluralidade de visões inerentes à vida coletiva. (NEVES, 2000, p. 112)

Há também a possibilidade de utilizar o museu virtual Museu da Pessoa ${ }^{3}$, que dispõe de um amplo banco de dados com narrativas de pessoas falando a respeito de suas experiências e seus cotidianos, passados e atuais. Além disso, pode-se também explorar as diversas realidades, costumes e culturas existentes nas regiões brasileiras para fazer uma análise sobre os cotidianos das pessoas de mesma faixa etária, mas de regiões diferentes. Este comparativo pode ser trabalhado de forma interdisciplinar com conteúdos da geografia, ciências e língua portuguesa.

Neves (2000) afirma que a utilização da História Oral enquanto metodologia de ensino propicia a formação e identificação dos processos identitários que constituem os sujeitos. A exemplo disso, pode-se citar as similaridades existentes entre uma pessoa idosa do bairro onde a escola está inserida e uma pessoa de outra região do Brasil, por meio de culturas em comum como moda de viola, bordado, movimentos estudantis.

$\mathrm{Na}$ impossibilidade de trazer pessoas de fora do cotidiano escolar para participar das atividades ou da inexistência de computadores e projetores para acessar o Museu da Pessoa, pode-se fazer uso da gravação de narrativas dos avós dos alunos, por meio de celulares, utilizando um roteiro que possibilite que a conversa flua sem que seja necessariamente uma entrevista de perguntas e respostas fechadas, podendo ser ouvidas em sala de aula.

Realizar entrevistas, sobretudo se forem semi-estruturadas, abertas, de histórias de vida etc. não é tarefa banal; propiciar situações de contato, ao mesmo tempo formais e informais, de forma a "provocar" um discurso mais ou menos livre, mas

\footnotetext{
3 Disponível em http://www.museudapessoa.net/pt/home Acesso em 16/03/2018
} 


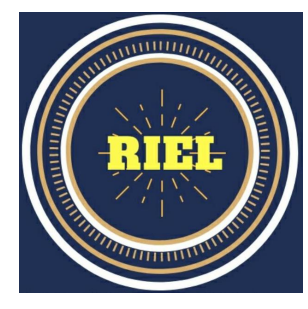

que atenda aos objetivos da pesquisa e que seja significativo no contexto investigado e academicamente relevante é uma tarefa bem mais complexa do que parece à primeira vista. (DUARTE, 2004, p. 216)

Além de mostrar aos alunos que nossas identidades são cotidianamente constituídas por uma rede de informações rica e amplamente densa, o professor também poderá debater sobre o porquê de certas histórias, tão ricas em detalhes e vivências, não entrarem nos livros de História, enquanto outras são incluídas - e assim problematizar a História dita oficial. Esta metodologia fará com que seja mais fácil para o aluno compreender que a História está inserida em seus (e em nossos) cotidianos de forma tal que, muitas vezes, poderá passar despercebida por um olhar não criterioso.

\subsection{História em quadrinhos e iconografias}

Outras metodologias do ensino de História que podem ser utilizadas em sala de aula são Revistas, Histórias em Quadrinhos (HQ) e Filmes. Pensar para além dos livros oficiais é uma forma de mostrar aos alunos que vivemos a história e ela está inserida em todos os nossos cotidianos sem que percebamos, por já estar interiorizada.

A vasta iconografia contida nas mais diversas revistas - não necessariamente os periódicos indexados que raramente fazem parte do cotidiano discente, mas as revistas comerciais encontradas nas bancas de jornais das cidades - pode favorecer o entendimento de que a própria roupa utilizada pelos alunos está dentro da moda, do padrão de beleza e daquilo compreendido como correto e socialmente aceitável; fato esse que merece ser problematizado em sala de aula.

Usemos como exemplo a moda, a vestimenta: 

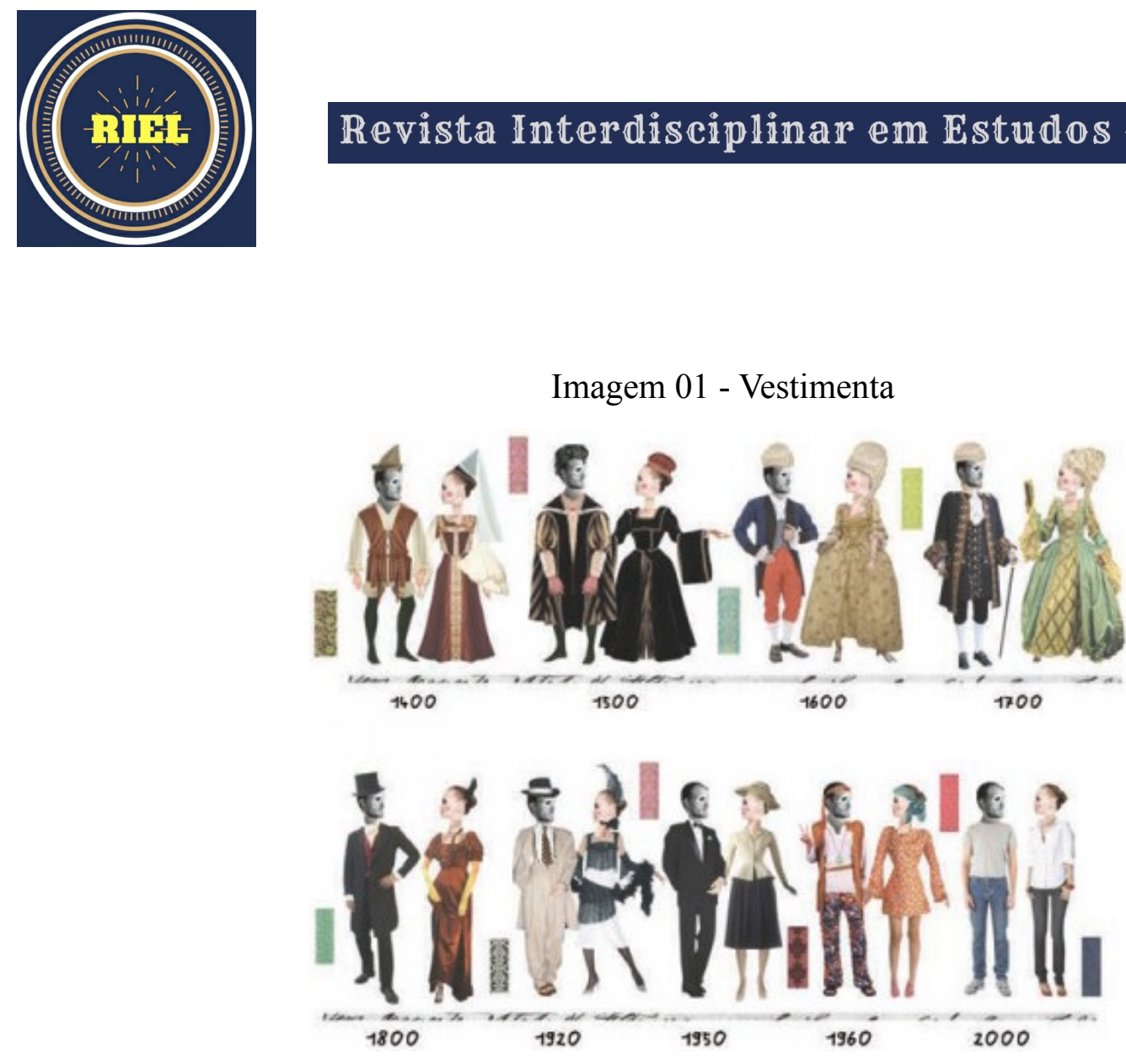

Fonte: Autor desconhecido

Partindo desta imagem como exemplo, desde o século XIII as vestimentas retratadas nos livros didáticos demonstram uma grande riqueza de tecidos, bem ornados, ajustados ao corpo por alfaiates, sempre em boa composição. Ainda nas iconografias mais recentes, também pode-se ver roupas bem trabalhadas, ainda que em menores quantidades. Enquanto se utilizava grande quantidade de roupas nos séculos passados, o século atual passou a ser mais minimalista.

Diversas são as problematizações que o professor pode levantar em sala com o objetivo de enriquecer as suas aulas: por que apenas pessoas de alto poder aquisitivo são representadas nas iconografias históricas? Onde estão as pessoas de classes sociais menos favorecidas e com ínfima possibilidade de utilizarem vestimentas como as representadas na imagem? Como a moda influencia o nosso comportamento em dias atuais? Quais discursos são existentes e estão presentes na utilização das vestimentas? Por que as iconografias priorizam uma determinada classe social em detrimento da outra? Por que as roupas se tornaram cada vez mais semelhantes e as distinções de gênero estão ficando tão fluídas que ambos usam o mesmo tipo de vestimenta na 
contemporaneidade? Quem cria e determina o que cada gênero pode usar? Para Peter Burke (2004), "embora os textos também ofereçam indícios valiosos, imagens constituem-se no melhor guia para o poder de representações visuais nas vidas religiosa e política de culturas passadas" (p. 17).

Atualmente, há uma grande quantidade de peças publicitárias implodindo as categorias de gênero para as vestimentas e criando roupas agêneras ou gêneros fluídos. Este posicionamento é algo revolucionário da indústria da moda ou está de acordo com as demandas sociais que buscam uma equidade de gêneros e representatividades?

O olhar crítico para a história da moda pode mostrar muitas informações às quais os livros oficiais não se atentam, por não serem consideradas interessantes e necessárias para o aprendizado da História. Entretanto, se o professor trabalhar esta questão, ele poderá enriquecer ainda mais o seu ensino e trazer novas discussões para que os alunos entendam que fazem parte da História e o seu ensino não está restrito ao passado, mas também ao presente, e que os alunos também são sujeitos e são constitutivos da História contemporânea.

Posto isto, existe a possibilidade de discutir as relações de gênero na sociedade, como as diferenças entre homem e mulher foram estruturadas e quais discursos ancoraram estas distinções. Da mesma forma, deve-se discutir como as discriminações contra as mulheres são historicamente mantidas. O que alguns veem como uma simples fotografia ou um simples desenho, um olhar mais crítico pode trabalhá-la buscando compreender quais discursos estão embutidos naquela iconografia em específica.

Tendo isso em mente, apesar de os padrões estabelecidos se constituírem como efeito das relações sociais, nada impede que manifestemos outros comportamentos: mulheres e homens podem fugir das expectativas e construir suas próprias identidades e funções sociais, já que não há um "eu" feminino ou masculino absoluto ou essencial. Há, porém, a pressão do meio agindo através dos discursos, das práticas socioideológicas, do senso comum e da própria estrutura social, influenciando os sistemas de crença. (KNOLL, 2012, p. 250)

As Histórias em Quadrinhos (HQ) também podem ser outra metodologia a ser trabalhada em sala de aula - obviamente que não se deve deixar de atentar-se ao fato de ser uma HQ. A vantagem desta metodologia está no fato de ela ser utilizada por diversos jovens que se interessam por este tipo de arte e ser de fácil acesso àqueles que se interessam, principalmente pelo forte apelo 
ilustrativo e pela linguagem irreverente. Para Testoni e Abib (2003), “a História em Quadrinho pode ser vista como uma fonte acessível, um instrumento que faz parte do cotidiano do discente, o que, em uma primeira fase, causaria um contato mais direto entre o aluno e o material utilizado" (p. 2).

Recomenda-se, também, a utilização de vídeos que possam ser facilmente adquiridos no Youtube ou a utilização de videoconferências via Skype para que os alunos tenham contato com pessoas de outras regiões para conhecer seus costumes locais. A escolha desta metodologia deve estar alinhada com o Projeto Político Pedagógico da escola e com os Parâmetros Curriculares Nacionais, pois estes servem de norte para que o professor possa estruturar sua aula.

A grande quantidade de conteúdo imagético existente no Youtube possibilita que outras formas metodológicas sejam aplicadas em sala de aula em consonância com a realidade discente, visto que a geração atual tem a internet inserida em seu cotidiano.

\subsection{História afro-brasileira}

A História contida nos livros e apostilas oficiais é aquela contada pelos vencedores, não pelos vencidos. Este fato acaba por induzir um viés diferente, e até mesmo perigoso, perante os fatos históricos contidos nestes respectivos materiais - portanto, é necessário ter um olhar criterioso e sempre inserir o debate sobre qual história é contada e o que ela realmente está contando.

Cito, como exemplo, a História dos Bandeirantes, que são abordados como heróis desbravadores do interior do Brasil, com direito a monumentos em suas homenagens, enquanto os negros e índios que foram assassinados por interesse dos portugueses colonizadores são parcialmente suprimidos e este genocídio é silenciado por meio da romantização e criação de heróis.

As culturas afro-brasileiras são de suma importância para fortalecer o movimento identitário por meio de suas musicalidades, suas religiosidades, suas vestimentas. Isto deve ser feito para que as diferenças sejam não apenas valorizadas, mas também que aqueles que se envergonham de sua cor, de sua origem e de seus signos tenham a oportunidade de conhecerem a sua história e 


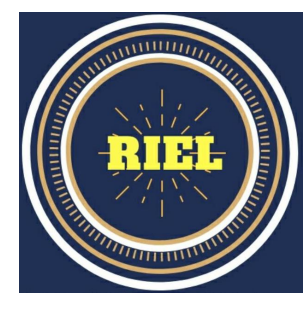

reconhecerem que foram postos historicamente às margens sociais e, assim, possibilitar que tenham orgulho de suas identidades por meio de empoderamentos diversos.

Ainda assim, muitas vezes, quando os livros retratam o continente africano no período colonial, o fazem como se fosse um país único, com um povo único e uma cultura única, invisibilizando as ricas e heterogêneas culturas existentes naquele continente.

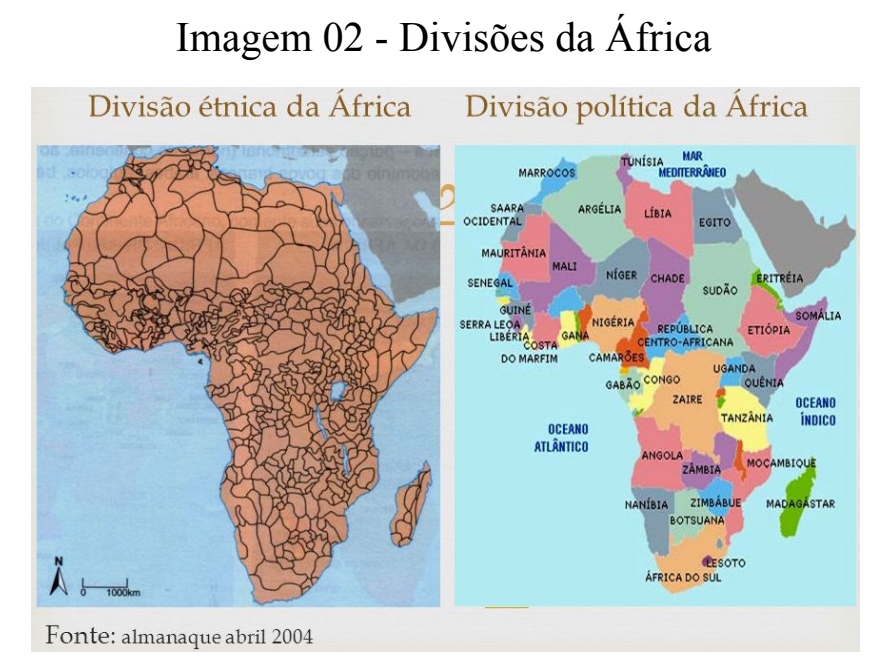

Fonte: Almanaque Abril (2004)

Está disponível no Youtube um excelente vídeo intitulado "Slave Trade In Two Minutes", que mostra, em pouco mais de dois minutos, como se deu o processo de sequestro de negros do continente africano e o seu envio ao continente americano. Se trabalhado conjuntamente com a música Haiti, de Caetano Veloso, será possível analisar como as questões do processo escravagista ainda ecoam no Brasil contemporâneo como, por exemplo, no trecho: E ao ouvir o silêncio sorridente de São Paulo; Diante da chacina; 111 presos indefesos, mas presos são quase todos pretos; Ou quase pretos, ou quase brancos quase pretos de tão pobres.

A utilização de rodas de conversa e palestras com representantes de movimentos sociais podem fomentar uma discussão, tanto com alunos quanto com professores, sobre como se deram seus processos identitários, quais discriminações vivenciam e as suas respectivas dificuldades. Para isso, estes representantes podem comparecer presencialmente ou participar virtualmente, por meio 


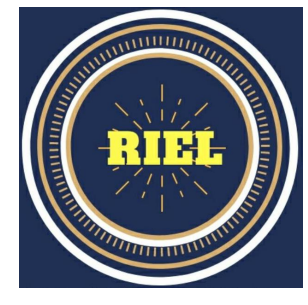

do Skype, para escolas que se localizem em regiões que não tenham tais movimentos sociais identitários organizados.

Com a discussão sobre como se deram os processos de exclusão social e como estes povos foram, e ainda são, marginalizados ao longo da História, cria-se um debate sobre como a História está presente em nossos cotidianos e a frequência com a qual estes processos violentos ainda se repetem atualmente, conforme imagem a seguir:

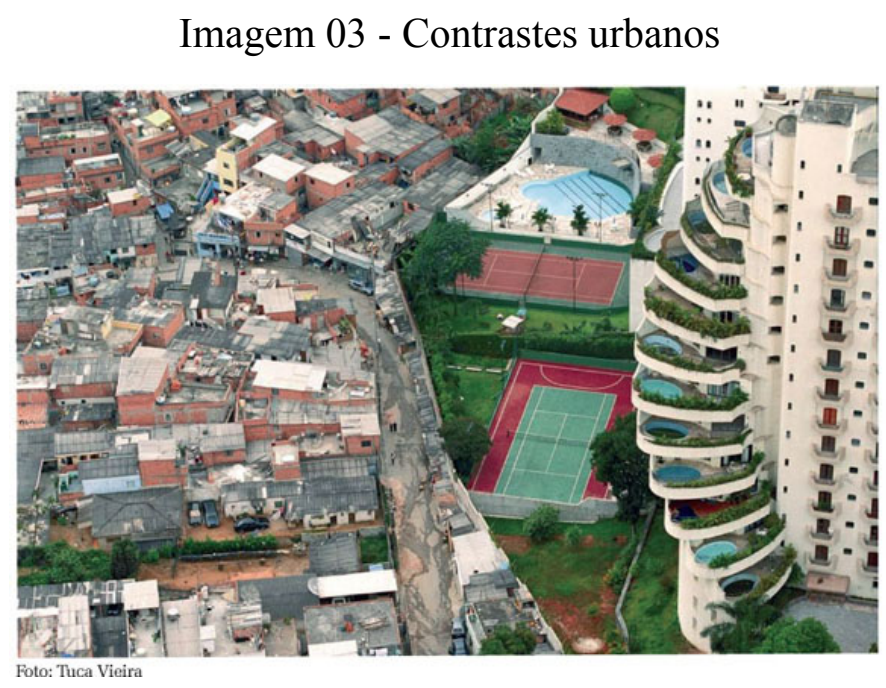

Fonte: Tuca Vieira (2004)

Para Gohn (2010), a favela de Paraisópolis, a segunda maior favela de São Paulo e quinta maior do Brasil, evidencia como estes processos de exclusões sociais históricas estão presentes ao nosso lado. A sua formação se deu por migrantes nordestinos, que vinham a São Paulo para trabalhar na construção civil e, ao fim dela, não tinham onde morar. Além do mais, pelas dificuldades relacionadas aos direitos trabalhistas e transporte público na época, muitos destes trabalhadores construíam moradias próximas às construções.

A interseccionalidade entre as questões etnicorraciais e regionais se faz presente e possibilita uma ampliação no debate sobre quais populações estão em situação de vulnerabilidade social e quais estão em situações privilegiadas, visto que na foto acima é possível reconhecer a diferença de acesso às infraestruturas de saneamento básico, entretenimento e esportes. 


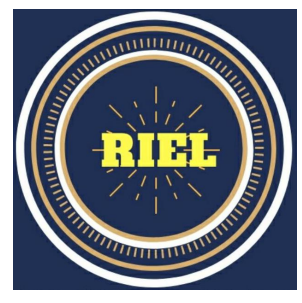

De acordo com Paixão, Rossetto, et al. (2010), a taxa bruta de escolaridade no ensino superior em 1988 de homens brancos era de 12,3\%, pretos e pardos de 3,1\%, enquanto de mulheres brancas era de 12,4\% e pretas e pardas 4,1\%. Em 1998, era de 15,0\% para homens brancos e 3,2\% para pretos e pardos, enquanto para mulheres brancas era de $18,4 \%$ e para as mulheres pretas e pardas era de 5,0\%. Já em 2008, as taxas tiveram uma acentuada elevação, visto que o PROUNI passou a vigorar desde 2003 e homens brancos representavam 31,7\% e homens pretos e pardos $13,0 \%$; já as mulheres brancas representavam 39,9\% enquanto as mulheres pretas e pardas 20,0\%.

Ainda que se possa ver um significativo aumento na última amostragem, a diferença existente na interseccionalidade entre raça e gênero aponta a imensa desigualdade existente entre homens e mulheres, assim como entre negros e brancos no Brasil.

\section{CONSIDERAÇÕES FINAIS}

O objetivo deste artigo foi pensar métodos e metodologias que dialoguem com o cotidiano da juventude na contemporaneidade para fazer com que o ensino de História seja mais crítico, participativo e interessante aos discentes. Para tanto, ao analisar os PCNs, compreender o que ele propõe e trazê-lo para os dias atuais, conclui-se que há diversas possibilidades de abordagens metodológicas a serem utilizadas com as séries do primeiro ciclo, ou seja, do Ensino Fundamental I.

Reconhecer as especificidades locais serve para que o ensino seja mais interessante aos discentes e eles possam compreender que são sujeitos históricos e estão inseridos em seus respectivos contextos familiares, escolares, regionais. A pluralidade cultural existente em uma sala de aula possibilita que outras metodologias sejam empregadas com o objetivo de valorizar as diferenças.

Olhar para si e para o outro, para as famílias, praças, ruas, bairros e todas as especificidades existentes no cotidiano discente são formas de fomentar o interesse deles pelo ensino de História, trazer a História para a contemporaneidade inserindo-a em suas realidades - não um conhecimento abstrato e intangível, mas algo real e palpável. 
Fomentar diversas possibilidades metodológicas é pensar em uma escola mais interessante partindo do reconhecimento de que aquela escola em que nós estudamos - e já era obsoleta - não dialoga mais com as necessidades e demandas da juventude, que requer algo mais dinâmico e inteligível.

Valorizar as diferenças é de fundamental importância para que a escola seja um local de debate sobre as realidades sociais e as suas consequentes desigualdades, assim como possibilita pensar em formas de mitigá-las, fazendo com que as vidas sejam mais vivíveis.

\section{REFERÊNCIAS}

ACOSTA, T. Morrer para nascer travesti: performatividades, escolaridades e a pedagogia da intolerância. Dissertação de Mestrado. Universidade Federal de São Carlos, 2016.

ALVES, L. A. M. A história local como estratégia para o ensino da história. Porto: Universidade do Porto, 2006.

BRASIL. Secretaria de Educação Fundamental. Parâmetros Curriculares Nacionais: História e geografia. Brasília: MEC/SEF, 1997.

BUTLER, J. Quadros de guerra: quando a vida é passível de luto? Trad. Sérgio Lamarão. Rio de Janeiro: Ed. Civilização Brasileira, 2015.

BURKE, P. Testemunha ocular: história e imagem. Bauru, SP: EDUSC, 2004.

CARVALHO, J. C. P. Etnocentrismo: inconsciente, imaginário e preconceito no universo das organizações educativas. Interface Comunicação, Saúde e Educ. Agosto, 1997.

COLL, C. Desenvolvimento psicológico e educação: transtornos do desenvolvimento e necessidades educativas especiais. $2^{\text {a }}$ Ed. Porto Alegre: Artmed, 2004.

DUARTE, R. Entrevistas em pesquisas qualitativas. Educar, Curitiba, n. 24, 2004, pp. 213-225.

FERNANDES, J. R. O. Um lugar na escola para a história local. Ensino em Re-vista, 4 (1), jan./ dez. 1995

GOHN, M. G. Morumbi: o contraditório bairro-região de São Paulo. Caderno CRH, Salvador, v. 23, n. 59, Maior/Ago, 2010.

HANISCH, C. The persona is political, 1969. Disponível em: http://www.carolhanisch.org/ CHwritings/PIP.html Acesso em 11 de janeiro de 2017. 
JODELET, D. Represéntation sociale: phénomèmes, concept et theorie. Paris: PUF, 1990

JUNQUEIRA, R. D. Pedagogia do armário: a normatividade em ação. Revista Retratos da Escola, Brasília, v. 7, n. 13, jul./dez. 2013, pp. 481-498.

KNOLL, G. F. Discursos de gênero na publicidade: análise crítica de textos publicitários em revistas. Sociais e Humanas, v. 25, n. 02, julho/dezembro 2012.

LE GOFF, J. História e memória. Campinas, SP: Ed. UNICAMP, 1990

LOSSIO, R. A. R.; PEREIRA, C. M. A importância da valorização da cultura popular para o desenvolvimento local. Salvador: UFBA, 2007

LOURO, G. L. Gênero, sexualidade e educação: uma perspectiva pós-estruturalista. Editora Vozes, 1998

MALANCHEN, J. O conceito de cultural: definição e compreensão a partir da teoria marxista. XI Jornada do Histedbr. A pedagogia histórico-crítica, a educação brasileira e os desafios de sua institucionalização. Cascavel, PR, 2013.

NADAI, E. O ensino de História e a "pedagogia do cidadão". In.: PINSKY, J. O ensino de História e a criação do fato. São Paulo: Editora Contexto, 14. ed, $2^{\mathrm{a}}$ reimpressão, 2009.

NEVES, L. A. Memória, história e sujeito: substratos da identidade. História Oral, n. 3, 2000.

PAIXAO, M.; ROSSETTO, I.; MONTOVANELE, F.; CARVANO, L. M. (Orgs.). Relatório anual das desigualdades raciais no Brasil 2009-2010: constituição cidadã, seguridade social e seus efeitos sobre as assimetrias de cor ou raça. Rio de Janeiro: Garamond Universitária, 2010.

ROSSO, S. D.; BANDEIRA, L.; COSTA, A. Pluralidade e diversidade das Ciências Sociais: uma contribuição para a epistemologia da ciência. Sociedade e Estado, Brasília, v. 17, n. 2, jul./dez. 2002, pp. 231-246.

SÊGA, R. A. O conceito de representação social nas obras de Denise Jodelet e Serge Moscovici. Anos 90, Porto Alegre, n. 13, julho de 2000.

TESTONI, L. A.; ABIB, M. L. V. S. A utilização de histórias em quadrinhos no ensino de física. IV Encontro Nacional de Pesquisa em Educação em Ciência, Bauru, SP: IV ENPEC, 2003.

YOUNG, M. Para que servem as escolas? Educ. Soc., Campinas, vol. 28, n. 101, set./dez. 2007, pp. 1287-1302. 